\title{
Polymers and Polymeric Materials in COVID-19 Pandemic: A Review
}

\author{
Ravindra V. Gadhave, S. K. Vineeth, Pradeep T. Gadekar \\ Department of Polymer and Surface Engineering, Institute of Chemical Technology, Mumbai, India \\ Email: ravi.gadhave1@gmail.com
}

How to cite this paper: Gadhave, R.V., Vineeth, S.K. and Gadekar, P.T. (2020) Polymers and Polymeric Materials in COVID-19 Pandemic: A Review. Open Journal of Polymer Chemistry, 10, 66-75.

https://doi.org/10.4236/ojpchem.2020.103004

Received: July 26, 2020

Accepted: August 25, 2020

Published: August 28, 2020

Copyright (c) 2020 by author(s) and Scientific Research Publishing Inc. This work is licensed under the Creative Commons Attribution International License (CC BY 4.0).

http://creativecommons.org/licenses/by/4.0/

(c) (i) Open Access

\begin{abstract}
The coronavirus disease 2019 (COVID-19) pandemic has been at its worst and the world is fighting to help global public health. In this aspect the role played by polymers and polymeric materials including plastics as the main material in medical devices, personal protective equipment for health care workers is huge. Advantages like mass production, lower cost and possibilities for sterilization and disinfection of the plastic materials make them an inevitable material in healthcare sector. Apart from plastics, anti-viral and anti-microbial coatings, polymeric nanocomposites and functional polymers have been introduced as a helping tool against COVID-19. This review focuses on the application of polymers, and polymeric materials in COVID-19 pandemic. Usage of plastics and its applications in healthcare and related sectors have been reviewed. The major challenges faced and future prospects on the usage of polymers have also been discussed.
\end{abstract}

\section{Keywords}

Polymers, Coatings, Novel Corona Virus, Nanomaterials, Functional Polymers, COVID-19

\section{Introduction}

The coronavirus disease 2019 (COVID-19) pandemic is an unprecedented global crisis that, by many calculations will have a deep and devastating economic and social impact on the scale of the Great Depression.

This crisis gave plastics a major image makeover amongst consumers; there is now a widely held outlook that plastic products are safer and cleaner than the recycled and reusable solutions being touted earlier and are at the forefront of the fight to contain the spread of contagion. Gone are the days when plastics will be spoken of only in terms of environmental leakage and a ban. Plastics will also 
benefit from increased spending on household cleaning, hygiene, and personal protection products, as well as higher domestic food consumption from a more home-based life. However, because this crisis will also cause deep destruction of personal wealth and economic uncertainty, consumers will also reduce discretionary spending on leisure, entertainment, travel and tourism, and eating out, which will impact related plastics consumption. Apart from these areas of the economy, major sectors including automotive and white goods will also face tremendous headwinds.

Protective garments used by health workers such as mask, caps, goggles and gowns are generally made from plastics and are used by health professionals in such outbreaks to reduce the risk of infection as it works as a barrier from bacteria and virus. The disposable plastic syringes have completely replaced alternative options. So far there are no alternative material has proven at par with the ease of utility and economics of all these varieties of medical grade plastics.

Plastics are valued in healthcare because of their versatility, sterile nature, and safety for patients and providers, cost effectiveness, ease of use, and utility in new applications and solutions. There is an almost endless list of medical applications for plastics as shown in Figure 1. Plastics will continue to offer exceptional solutions in the future [1]. With increasing use of plastics in healthcare industry, the government and regulators should enforce right disposal and recycling practices to avoid contamination and spread of COVID-19 infection.

\section{Plastics Used in Personal Protective Equipment (PPE)}

The capital of Hubei province in China, Wuhan, became the center of an outbreak

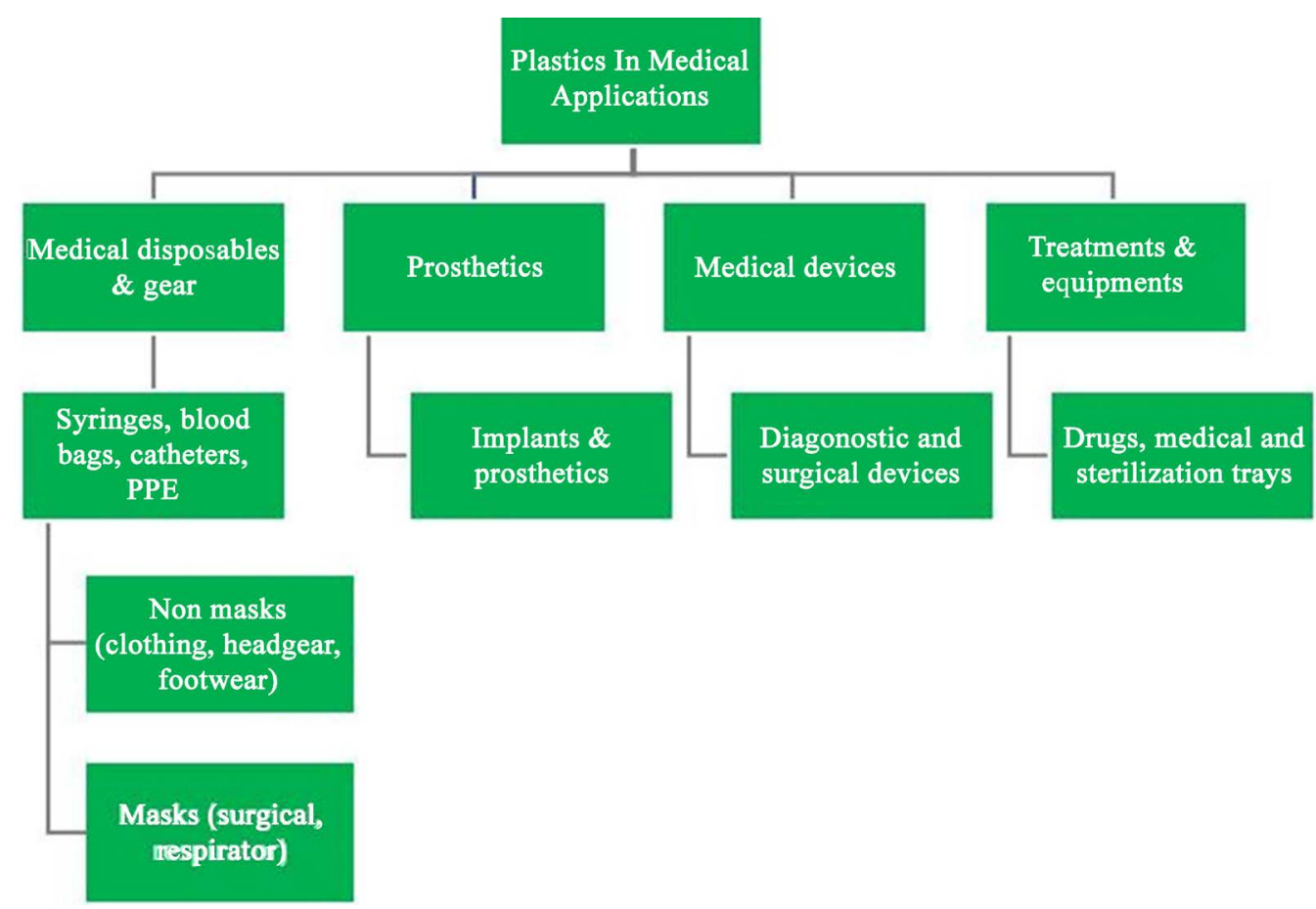

Figure 1. Plastics in medical application. 
of pneumonia of unknown cause in December 2019 [2]. This outbreak of pneumonia was the emergence of the novel coronavirus (SARS-CoV-2 later named coronavirus disease 2019 or COVID-19) and continues summing cases in every continent in only a few months. The World Health Organization (WHO) situation report 58 [3], indicated that, as of the $18^{\text {th }}$ of March, there had been 191,127 confirmed cases and 7807 deaths around the world. Due to its significant impact, the emergence of this novel coronavirus has been declared a pandemic. The executive governmental branch of the U.S. has recently invoked the Defense Production Act to increase the domestic production of medical supplies necessary for fighting the current pandemic [4] [5].

Health regulatory bodies worldwide like Indian Council of Medical Research (ICMR), WHO and United States Centers for Disease Control and Prevention (CDC) have laid down strict protocols to be followed by healthcare workers. They chiefly consist of using personal protective equipment (PPE) like masks, respirators, gloves, coveralls, safety goggles, face shields, foot cover and hair cover. Amazingly, all these PPE are made of plastics. A variety of plastics including some commodity and some engineering plastics like low density polyethylene (LDPE), polypropylene(PP), polyvinyl chloride (PVC), nylon, polyethylene terephthalate (PET) and polycarbonate (PC) are used to make various PPEs. In the last few days, plasma transfusion from COVID recovered patients has been found to help in the treatment of infected patients. This blood plasma is collected from recovered patients using the process of plasmapheresis. Such membranes used for plasmapheresis are made up of polyethersulfone (PES), polymethylmethacrylate (PMMA) or even PP [6]. Also, Tyvek ${ }^{\mathrm{TM}}$, a product made by Dupont consisting of flash spun high density polyethylene (HDPE) is widely used for making full body suits that cover head to toe for workers who are exposed to highly contaminated environments.

According to a study conducted by ASSOCHAM (Associated Chamber of Commerce) and Velocity, India is going to generate 775.5 tones of medical waste per day by the year 2022 at a Compounded Annual Growth Rate of 7\% [7] [8]. Currently, 550.9 tones of medical waste are generated daily that are disposed off as per the Bio-medical Waste Management Rules-2016 (BMW-2016) laid down by the Ministry of Environment, Forest and Climate Change. These projections were made prior to the COVID-19 episode. It is only fathomable that the plastic bio-waste generation will surge several times due to its indispensable use during the COVID-19 crisis. A United Nations Environment Programme (UNEP) estimates about $0.5 \mathrm{~kg}$ of plastic bio-waste is generated per hospital bed per day during the COVID-19 crisis [9] [10].

\section{Antimicrobial Polymers and Coatings}

The purpose of this invocation will likely be used to drive private businesses to increase U.S. production of Personal Protective Equipment (PPE) and other critical medical supplies and devices. The Food and Drug Administration (FDA) 
reported that the COVID-19 outbreak would likely impact the medical product supply chain, including potential disruptions to supply or shortages of critical medical products in the U.S. [11] Additive manufacturing (i.e., 3D Printing) is uniquely well positioned to support the shortage of critical medical devices [11]. Advancements in additive manufacturing techniques and development of antimicrobial polymers, offer the possibility of printing and customizing a wide range of medical devices.

The critical limitation for the use of polymeric materials to additively manufacture critical medical devices is the material contamination by bacteria and viruses [12]. Previous investigations have shown strong evidence of the use of different forms of copper as a biocidal agent [13]-[19] and the use of copper nanocomposites to enhance the antimicrobial properties of polymers used in the development of medical devices [16] [17] [18] [19] [20].

The development of an affective antimicrobial polymer for additive manufacturing seems increasingly critical due to the extensive use of polymers in the prototyping of critical medical devices. It has been suggested that the addition of nanoparticles of copper to polymers and the resulting antimicrobial properties have promising applications to the development of medical devices associated with bacterial growth. Furthermore, previous investigations have used copper nanocomposites to enhance the antimicrobial properties of polymers used in injection moulding and additive manufacturing to develop medical devices. The strong biocidal effects of copper found by Holbrook et al., are supported by previous investigations that have examined the viral deactivation properties of copper oxide particles infused in textiles. Borkow et al., found that the addition of copper oxide into respiratory protective face masks resulted in potent anti-influenza properties against human influenza A (H1N1) and avian influenza (H9N2) without altering their physical barrier properties [21]. However, the use of commercially available antimicrobial materials and the implementation of printing specifications settings resulting infused extruded layers, can stop molecules down to $0.000282 \mu \mathrm{m}$, significantly smaller than viruses, such as the virus associated to COVID-19 $(0.03 \pm 0.01 \mu \mathrm{m})$ [22]. The recent elaboration of thermoplastics blends with antimicrobial copper nanocomposites is a direct and practical approach to produce antimicrobial thermoplastics. The antimicrobial properties of copper, has been enhanced by two main factors. The first is reducing the size of the copper particles to the nanoscale $(10 \mathrm{~nm})$ increasing the volume of copper that can be added to a given solution or matrix as well as increasing the total surface area of the particles releasing a higher amount of metal ions. The second is incorporation of copper nanoparticles into polymer matrices. Copper nanoparticles on a polymer structure present a stronger antimicrobial effect than microparticles or metal surfaces by facilitating the adsorption of microorganisms on the polymer surface triggering the diffusion of water through the polymer matrix. In turn, water with dissolved oxygen reaches the surface of embedded copper nanoparticles allowing the corrosion processes to take effect 
by releasing copper ions. Copper ions reach the composite surface damaging the microorganism cell membrane allowing the metal ions to enter the cell and damage DNA, RNA, and other bio-molecules. The copper ions and associated hydroxyl radicals produce DNA denaturalization damaging helical structures. This DNA and RNA damage has been shown to deactivate viruses. Copper oxide affected free viruses, virions being formed within the cytoplasm of cells during the cell exposure to copper, and virions prior to their budding from the cells [23] [24] [25]. Thus, the unprecedented need for biocidal polymers during a pandemic and the high accessibility of additive manufacturing equipment and materials can drive the implementation of this technology to revolutionize the manufacturing of critical medical devices when the supply chain is insufficient. Thus, the use of additive manufacturing using antimicrobial polymers to develop reusable face masks can significantly reduce the viral load remaining on the mask protecting the end-users from contamination during prolonged mask wearing [25].

\section{Anti-Viral Coating}

Literature survey shows that the nanoparticles of various metals and metal oxides like Zinc Oxide ( $\mathrm{ZnO})$ nanoparticles [26], Cuprous Oxide $(\mathrm{CuO})$ nanoparticles [27], Silver (Ag) nanoparticles [28] [29], Nano-sized Copper (I) Iodide particles $(\mathrm{CuI})$, Gold nanoparticles on Silica $\left(\mathrm{Au}-\mathrm{SiO}_{2}\right)$ nanoparticles and also some Quaternary ammonium cations are very promising to inactivate the virus and are well proven. The plausible ways of functioning of the doped nano active materials against COVID-19 viruses would be as follow:

- As Ag nanoparticles have been reported to inhibit the replication of virus nucleotides, the main mechanism of its being virulent. It binds to electron donor groups such as Sulfur, Oxygen, and Nitrogen commonly found in enzymes within the microbe. This causes the enzymes to be denatured thus effectively incapacitating the energy source of the cell and the microbe will quickly die;

- The cationic silver $\left(\mathrm{Ag}^{+}\right)$might work to inactivate the SARS-CoV-2 by interacting with its surface (spike) protein $S$ based on its charge like it works in HIV, Hepatitis viruses, etc [29] [30].

\section{Functional Polymers}

The Prep FilerTM is a new kit recently introduced by Applied Bio-systems for DNA extraction from a wide range of forensic samples. This kit was tested for the performance against other commonly used commercially available kits on a variety of real forensic casework samples: bloodstains on different substrates, washed bloodstains, semen stains, saliva stains, hairs, bones, tissues, nails, and prints after chemical treatments, skin swabs. The Prep FilerTM kit is a new system developed for isolation of genomic DNA from a variety of forensic samples. It uses polymer-embedded magnetic particles, much smaller than other ones that offer a large surface area with higher and efficient DNA binding capacity resulting in a maximum DNA recovery [31]. 


\section{Polymer Nanocomposites and Nanomaterials}

Research on highly effective antiviral drugs is essential for preventing the spread of infections and reducing losses. Recently, many functional nanoparticles have been shown to possess remarkable antiviral ability, such as quantum dots, gold and silver nanoparticles, nanoclusters, carbon dots, graphene oxide, silicon materials, polymers and dendrimers. Despite their difference in antiviral mechanism and inhibition efficacy, these functional nanoparticles-based structures have unique features as potential antiviral candidates. In [32] highlight the antiviral efficacy and mechanism of these nanoparticles. Nanotechnology has penetrated all aspects of virus research [33] [34] [35] [36] [37]. Firstly, nanotechnology-based probes have been widely used in virus detection, leading to the production of various biosensors and bioelectronics based on novel functional nanoparticles [38] [39]. Secondly, many nanomaterials have been prepared by using various virions and virus-like particles as templates [40] [41] [42] [43], making biocompatibility and biosynthesis methodology a focus in recent biochemical research. Thirdly, intensive endeavors have been devoted to the development of fluorescent nano-probes and their applications in research of the molecular mechanism of virus-infected cells [44] [45] [46]. Finally, more and more functionalized nanoparticles have been reported as highly potent inhibitors of viral proliferation. Since the first three research areas have been summarized and reported as shown in Table 1 [47], this focuses on the inhibitory effect of functional nanoparticles on viruses and the related mechanisms [47].

\section{Nanotech Coating for Mask Fabric}

The coronavirus, it turns out, is no different. Curran, a professor of physics at the University of Houston who is well-known for his work commercializing

Table 1. Typical antiviral mechanisms for nanoparticles [47].

\begin{tabular}{ccc}
\hline Nanomaterials & Virus & Mechanism \\
\hline Graphene oxide & $\begin{array}{c}\text { Respiratory syncytial } \\
\text { virus }\end{array}$ & Directly inactivate virus and inhibit attachment \\
Nanogel & PRRSV & Shield attachment and penetration \\
Silver nanoparticle & Herpesvirus & Affect viral attachment \\
Graphene oxide & Herpesvirus & Attachment inhibition \\
Gold nanoparticles & Herpesvirus & Prevent viral attachment and penetration \\
Nano-carbon & Herpesvirus & Inhibit virus entry at the early stage \\
Silicon nanoparticles & Influenza A & Reduce the amount of progeny virus \\
Ag2S nanoclusters & Coronavirus & Block viral RNA synthesis and building \\
Copper oxide & Zika virus & As antigen micro carriers for Zk2 peptide of ZIKV \\
nanoparticles & H5N1 Influenza virus & Promote the expression of cytokines \\
Zirconia nanoparticles & Inhibit virus only after viral entry into host cells \\
\hline Zinc oxide nanoparticles & H1N1 Influenza virus & Int \\
\hline
\end{tabular}


nanotechnologies, is using a hydrophobic coating he developed almost a decade ago to improve the ability of surgical masks to protect against transmission of the virus. "Standard masks are somewhat porous, and especially if they get wet, they can allow the virus to penetrate", Curran said, noting that goes both ways-people infected with the virus could spread it even through a mask, while people who aren't sick could still become infected, despite wearing a mask. Curran first launched a nanotechnology business in 2013; he currently has a company, Integricote, based at the UH Technology Bridge focused on manufacturing sealers for masonry, wood and concrete. But he has worked with nanotech coatings for fabrics since 2011, technology that he now is using to demonstrate a way to provide more protection against SARS and COVID-19.

A process of fabricating the waterproof coating may include selecting a substrate, utilizing a sol-gel comprising a silane or silane derivative and metal oxide precursor to coat the substrate, and optionally coating the substrate with a hydrophobic chemical agent and/or other chemical agents to create a surface with nanoscopic or microscopic features. The process may utilize an all solution process or controlled environment for fabricating self-cleaning and waterproof coating that prevent wetting or staining of a substrate, or may utilize a controlled environment [48].

\section{Conflicts of Interest}

The authors declare no conflicts of interest regarding the publication of this paper.

\section{References}

[1] How Is Polymer Demand Impacted by the COVID-19 Pandemic? https://ihsmarkit.com/research-analysis/how-is-polymer-demand-impacted-by-thecovid19-pandemic.html

[2] WHO (2020) Coronavirus Disease (COVID-19) Pandemic. https://www.who.int/emergencies/diseases/novel-coronavirus-2019

[3] WHO (2020) Coronavirus Disease 2019 (COVID-19) Situation Report-58. https://www.who.int/docs/default-source/coronaviruse/situation-reports/20200318sitrep-58-covid-19.pdf?sfvrsn=20876712_2

[4] FEMA (1950) The Defense Production Act of 1950, as Amended (50 U.S.C. App. 2061 et seq.). https://www.fema.gov/media-library/assets/documents/15666

[5] Zuniga, J.M. and Cortes, A. (2020) The Role of Additive Manufacturing and Antimicrobial Polymers in the COVID-19 Pandemic. Expert Review of Medical Devices, 17, 477-481. https://doi.org/10.1080/17434440.2020.1756771

[6] Bohler, J., Donauer, K., Koster, W., Schollmayer, P., Wieland, H. and Horl, W. (1991) Biocompatibility of Four Plasmapheresis Membranes in Patients Treated for Hypercholesterolemia. Journal of Nephrology, 11, 479-485. https://doi.org/10.1159/000168363

[7] https://www.cdc.gov/coronavirus/2019-ncov/downloads/COVID-19_PPE_illustrati ons-p.pdf

[8] https://economictimes.indiatimes.com/industry/healthcare/biotech/healthcare/india 
-to-generate-775-5-tonnesof-medical-waste-daily-by-2020-study/articleshow/63426 284.cms?from $=\mathrm{mdr}$

[9] Healthcare Waste: What to Do with It? https://www.unenvironment.org/news-and-stories/story/healthcare-waste-what-do-it

[10] Bhatnagar, M.P. and Mahanwar, P.A. (2020) Dealing with Medical Plastic Waste: An Aftermath of COVID-19. Polymer Communiqué Magazine.

[11] FDA (2020) Coronavirus (COVID-19) Supply Chain Update. https://www.fda.gov/news-events/press-announcements/coronavirus-covid-19-sup ply-chain-update

[12] Gonzalez-Henriquez, C.M., Sarabia-Vallejos, M.A. and Rodriguez Hernandez, J. (2019) Antimicrobial Polymers for Additive Manufacturing. International Journal of Molecular Sciences, 20, 1210. https://doi.org/10.3390/ijms20051210

[13] Borkow, G., Sidwell, R.W., Smee, D.F., et al. (2007) Neutralizing Viruses in Suspensions by Copper Oxide-Based Filters. Antimicrobial Agents and Chemotherapy, 51, 2605-2607. https://doi.org/10.1128/AAC.00125-07

[14] Borkow, G., Zhou, S.S., Page, T. and Gabbay, J. (2010) A Novel Anti-Influenza Copper Oxide Containing Respiratory Face Mask. PLoS ONE, 5, e11295. https://doi.org/10.1371/journal.pone.0011295

[15] VanDoremalen, N., Bushmaker, T., Morris, D.H., et al. (2020) Aerosol and Surface Stability of SARS-CoV-2 as Compared with SARS-CoV-1. The New England Journal of Medicine, 382, 1564-1567. https://doi.org/10.1101/2020.03.09.20033217

[16] Palza, H., Nunez, M., Bastias, R. and Delgado, K. (2018) In Situ Antimicrobial Behavior of Materials with Copper-Based Additives in a Hospital Environment. International Journal of Antimicrobial Agents, 51, 912-917. https://doi.org/10.1016/j.ijantimicag.2018.02.007

[17] Palza, H., Quijada, R. and Delgado, K. (2015) Antimicrobial Polymer Composites with Copper Micro- and Nanoparticles: Effect of Particle Size and Polymer Matrix. Journal of Bioactive and Compatible Polymers, 30, 366-380. https://doi.org/10.1177/0883911515578870

[18] Zuniga, J. (2018) 3D Printed Antibacterial Prostheses. Applied Sciences, 8, 1651. https://doi.org/10.3390/app8091651

[19] Palza, H. (2015) Antimicrobial Polymers with Metal Nanoparticles. International Journal of Molecular Sciences, 16, 2099-2116. https://doi.org/10.3390/ijms16012099

[20] Lamprou, D.A. (2020) Emerging Technologies for Diagnostics and Drug Delivery in the Fight against COVID-19 and Other Pandemics. Expert Review of Medical Devices. https://doi.org/10.1080/17434440.2020.1792287

[21] Kondor, S., Grant, C.G., Liacouras, P., et al. (2013) On Demand Additive Manufacturing of a Basic Surgical Kit. Journal of Medical Devices, 7, Article ID: 030916. https://doi.org/10.1115/1.4024490

[22] Barnard, D.L. and Kumaki, Y. (2011) Recent Developments in Anti-Severe Acute Respiratory Syndrome Coronavirus Chemotherapy. Future Virology, 6, 615-631. https://doi.org/10.2217/fvl.11.33

[23] Gruber, P.R. (2001) Commodity Polymers from Renewable Resources: Polylactic Acid. https://www.ncbi.nlm.nih.gov/books/NBK44131

[24] Chuang, K.C.G., Joseph, E., Draper, R.D., Shin, Euy-Sik, E., Patterson, C. and Santelle, T.D. (2015) Additive Manufacturing and Characterization of Ultem Polymers and Composites. https://ntrs.nasa.gov/search.jsp? $\mathrm{R}=20160001352$

[25] Gadi, B. and Jeffrey, G. (2005) Copper as a Biocidal Tool. Current Medicinal Che- 
mistry, 12, 2163-2175. https://doi.org/10.2174/0929867054637617

[26] Tavakoli, A., Ataei-Pirkooh, A., Mm Sadeghi, G., Bokharaei-Salim, F., Sahrapour, P. and Kiani, S.J. (2018) Polyethylene Glycol-Coated Zinc Oxide Nanoparticle: An Efficient Nano Weapon to Fight against Herpes Simplex Virus Type 1. Nanomedicine, 13, 2675-2690. https://doi.org/10.2217/nnm-2018-0089

[27] Hang, X., Peng, H., Song, H., Qi, Z., Miao, X. and Xu, W. (2015) Antiviral Activity of Cuprous Oxide Nanoparticles against Hepatitis C Virus in Vitro. Journal of Virological Methods, 222, 150-157. https://doi.org/10.1016/j.jviromet.2015.06.010

[28] Elechiguerra, J.L., Burt, J.L., Morones, J.R., Camacho-Bragado, A., Gao, X., Lara, H.H. and Yacaman, M.J. (2005) Interaction of Silver Nanoparticles with HIV-1. Journal of Nanobiotechnology, 3, 6. https://doi.org/10.1186/1477-3155-3-6

[29] Galdiero, S., Falanga, A., Vitiello, M., Cantisani, M., Marra, V. and Galdiero, M. (2011) Silver Nanoparticles as Potential Antiviral Agents, Molecules, 16, 8894-8918. https://doi.org/10.3390/molecules16108894

[30] https://www.coatingsworld.com/content-microsite/cw_covid-19/2020-04-15/anti-viral -surface-coating-to-prevent-spread-of-novel-coronavirus-covid-19-through-touch

[31] Munoz, A., Sigwalt, D., Illescas, B.M., Luczkowiak, J., Rodriguez-Perez, L., et al. (2016) Synthesis of Giant Globular Multivalent Glycofullerenes as Potent Inhibitors in a Model of Ebola Virus Infection. Nature Chemistry, 8, 50-57. https://doi.org/10.1038/nchem.2387

[32] Lembo, D. and Cavalli, R. (2010) Nanoparticulate Delivery Systems for Antiviral Drugs. Antiviral Chemistry and Chemotherapy, 21, 53-70. https://doi.org/10.3851/IMP1684

[33] Liu, X., Zhang, L., Mu, Y., Li, X., Liu, C., Lv, P., Zhang, Y., Cheng, T., Yuan, Q., Xia N., Chen, X. and Liu, G. (2018) Bioinspired Artificial Nanodecoys for Hepatitis B Virus. Angewandte Chemie International Edition, 57, 12499-12503. https://doi.org/10.1002/anie.201807212

[34] Gansukh, E., Anthonydhason, V., Jung, S., Kim, D.H., Muthu, M., Gopal, J. and Chun, S. (2018) Nanotherapeutic Anti-Influenza Solutions: Current Knowledge and Future Challenges. Journal of Cluster Science, 29, 933-941. https://doi.org/10.1007/s10876-018-1417-z

[35] Lembo, D., Donalisio, M., Civra, A., Argenziano, M. and Cavalli, R. (2018) Nanomedicine Formulations for the Delivery of Antiviral Drugs: A Promising Solution for the Treatment of Viral Infections. Expert Opinion on Drug Delivery, 15, 93-114. https://doi.org/10.1080/17425247.2017.1360863

[36] Elberry, M.H., Darwish, N.H.E. and Mousa, S.A. (2017) Hepatitis C Virus Management: Potential Impact of Nanotechnology. Virology Journal, 14, Article No. 88. https://doi.org/10.1186/s12985-017-0753-1

[37] O’Dowd, K., Nair, K.M., Forouzandeh, P., Mathew, S., Grant, J., Moran, R., Bartlett, J., Bird, J. and Pillai, S.C. (2020) Face Masks and Respirators in the Fight against the COVID-19 Pandemic: A Review of Current Materials, Advances and Future Perspectives. Materials, 13, 3363. https://doi.org/10.3390/ma13153363

[38] Chen, L., Zhang, X.W., Zhou, G.H., Xiang, X., Ji, X.H., Zheng, Z.H., He, Z.K. and Wang, H.Z. (2012) Simultaneous Determination of Human Enterovirus 71 and Coxsackievirus B3 by Dual-Color Quantum Dots and Homogeneous Immunoassay. Analytical Chemistry, 84, 3200-3207. https://doi.org/10.1021/ac203172x

[39] Daaboul, G.G., Yurt, A., Zhang, X., Hwang, G.M., Goldberg, B.B. and Unlu, M.S. (2010) High Throughput Detection and Sizing of Individual Low-Index Nanopar- 
ticles and Viruses for Pathogen Identification. Nano Letters, 10, 4727-4731. https://doi.org/10.1021/nl103210p

[40] Luo, K., Jung, S., Park, K.H. and Kim, Y.R. (2018) Microbial Biosynthesis of Silver Nanoparticles in Different Culture Media. Journal of Agricultural and Food Chemistry, 66, 957-962. https://doi.org/10.1021/acs.jafc.7b05092

[41] Lee, S.Y., Krishnamurthy, S., Cho, C.W. and Yun, Y.S. (2016) Biosynthesis of Gold Nanoparticles Using Ocimum Sanctum Extracts by Solvents with Different Polarity. ACS Sustainable Chemistry \& Engineering, 4, 2651-2659. https://doi.org/10.1021/acssuschemeng.6b00161

[42] Yin, Y., Yang, X.Y., Hu, L.G., Tan, Z.Q., Zhao, L.X., Zhang, Z., Liu, J.F. and Jiang, G.B. (2016) Superoxide-Mediated Extracellular Biosynthesis of Silver Nanoparticles by the Fungus Fusarium Oxysporum. Environmental Science \& Technology Letters, 3, 160-165. https://doi.org/10.1021/acs.estlett.6b00066

[43] Zhang, Y., Ke, X.L., Zheng, Z.H., Zhang, C.L., Zhang, Z.F., Zhang, F.X., Hu, Q.X., He, Z.K. and Wang, H.Z. (2013) Encapsulating Quantum Dots into Enveloped Virus in Living Cells for Tracking Virus Infection. ACS Nano, 7, 3896-3904. https://doi.org/10.1021/nn305189n

[44] Pan, H., Zhang, P.F., Gao, D.Y., Zhang, Y.J., Li, P., Liu, L.L., Wang, C., Wang, H.Z., Ma, Y.F. and Cai, L.T. (2014) Noninvasive Visualization of Respiratory Viral Infection Using Bio-Orthogonal Conjugated near Infrared-Emitting Quantum Dots. ACS Nano, 8, 5468-5477. https://doi.org/10.1021/nn501028b

[45] Luo, R., Fang, L.R., Jin, H., Wang, D., An, K., Xu, N.Z., Chen, H.C. and Xiao, S.B. (2014) Label-Free Quantitative Phosphoproteomic Analysis Reveals Differentially Regulated Proteins and Pathway in PRRSV-Infected Pulmonary Alveolar Macrophages. Journal of Proteome Research, 13, 1270-1280.

https://doi.org/10.1021/pr400852d

[46] White, K.M., Jr., P.A., Wang, H., Jesus, P.D.D., Manicassamy, B., García-Sastre, A., Chanda, S.K., DeVita, R.J. and Shaw, M.L. (2018) Broad Spectrum Inhibitor of Influenza A and B Viruses Targeting the Viral Nucleoprotein. ACS Infectious Diseases, 4, 146-157. https://doi.org/10.1021/acsinfecdis.7b00120

[47] Chen, L. and Liang, J. (2020) An Overview of Functional Nanoparticles as Novel Emerging Antiviral Therapeutic Agents. Materials Science and Engineering. C, 112, Article ID: 110924. https://doi.org/10.1016/j.msec.2020.110924

[48] Curran, S., Liao, K.-S., Alley, N., Haldar, A., Wang, A. and Tatarin, R. (2014) Waterproof Coating with Nanoscopic Microscopic Features and Methods of Making Same. US9694388B2. 